\title{
Chitin Fiber and Chitosan 3D Composite Rods
}

\author{
Zhengke Wang, ${ }^{1}$ Qiaoling Hu, ${ }^{1}$ and Lei Cai ${ }^{2}$ \\ ${ }^{1}$ Department of Polymer Science and Engineering, Key Laboratory of Macromolecule Synthesis and Functionalization, \\ Zhejiang University, Ministry of Education, Hangzhou 310027, China \\ ${ }^{2}$ Department of Materials Science and Engineering, The University of Tennessee, Knoxville, TN 37996, USA
}

Correspondence should be addressed to Qiaoling Hu, huql@zju.edu.cn

Received 15 March 2010; Accepted 21 April 2010

Academic Editor: Shanfeng Wang

Copyright (c) 2010 Zhengke Wang et al. This is an open access article distributed under the Creative Commons Attribution License, which permits unrestricted use, distribution, and reproduction in any medium, provided the original work is properly cited.

Chitin fiber (CHF) and chitosan (CS) 3D composite rods with layer-by-layer structure were constructed by in situ precipitation method. CHF could not be dissolved in acetic acid aqueous solution, but CS could be dissolved due to the different deacetylation degree (D.D) between CHF and CS. CHF with undulate surfaces could be observed using SEM to demonstrate that the sufficiently rough surfaces and edges of the fiber could enhance the mechanical combining stress between fiber and matrix. XRD indicated that the crystallinity of CHF/CS composites decreased and CS crystal plane d-spacing of CHF/CS composites became larger than that of pure CS rod. TG analysis showed that mixing a little amount of CHF could enhance thermal stability of CS rod, but when the content of CHF was higher than the optimum amount, its thermal stability decreased. When $0.5 \%$ CHF was added into CS matrix, the bending strength and bending modulus of the composite rods arrived at 114.2 MPa and 5.2 GPa, respectively, increased by $23.6 \%$ and $26.8 \%$ compared with pure CS rods, indicating that CHF/CS composite rods could be a better candidate for bone fracture internal fixation.

\section{Introduction}

Chitin, a natural polymer from marine resources [1], is found particularly in the shells of crustaceans such as crab and shrimp, the cuticles of insects, and the cell walls of fungi and is one of the most abundant biopolymers next to cellulose [2]. The shells contain $15 \%-40 \%$ chitin and its amount in the whole marine environment has been estimated at 1560 million tons [3, 4]. It has attracted more and more attention nowadays, due to its abundant resources, friendliness to the environment, and potential to substitute some petrochemicals [1]. Commercially, chitin is obtained at a relatively low cost from the wastes of the seafood processing industry. Briefly, the process consists of deproteinization of the raw shell material in a dilute $\mathrm{NaOH}$ solution and decalcification in a dilute $\mathrm{HCl}$ solution [5]. Chitosan (CS), a fully or partially deacetylated form of chitin, has become important materials in various fields, including medicine, biochemistry, analytical chemistry, and chemical engineering [6]. This derivative product with higher degree of deacetylation (D.D) results from the reaction of chitin with alkali (40\%-45\% $\mathrm{NaOH}$ solution) at elevated temperatures at prolonged exposures $[5,7]$.
Chitin and CS are polymers consisted of $\mathrm{N}$-acetylglucosamine and $\mathrm{N}$-glucosamine units randomly or block distributed throughout the biopolymer chain (Figure 1) [7, 8]. They are characterized by D.D; when D.D is lower than $50 \%$, the biopolymer is named chitin. Conversely, when D.D is higher than $50 \%$, the biopolymer is named CS [8]. The D.D is affected by both the source of the biopolymer and the preparation methods and may range from as low as $30 \%$ to almost $100 \%$ [9]. It is a key parameter that influences the physicochemical properties of chitin and CS, such as solubility, surface energy, chain conformation, and biological properties $[9,10]$. Chitin is not soluble in common solvents because of the strong intermolecular hydrogen bonding, while it is soluble only in special solvents such as hexafluoroacetone and $\mathrm{N}, \mathrm{N}$-dimethylacetamide (DMAc) containing $5 \%-8 \% \mathrm{LiCl}$ [3]. CS is insoluble in either organic solvents or water; however, it could be readily dissolved in weak acidic solutions, due to the presence of amino groups. The solubilization occurs by protonation of the $-\mathrm{NH}_{2}$ on the $\mathrm{C}-2$ position of the $\mathrm{D}$-glucosamine repeat unit, whereby the polysaccharide is converted to a polyelectrolyte in acidic media [11]. To obtain a soluble product, the D.D of CS should reach $80 \%-85 \%$ or higher [5]. 


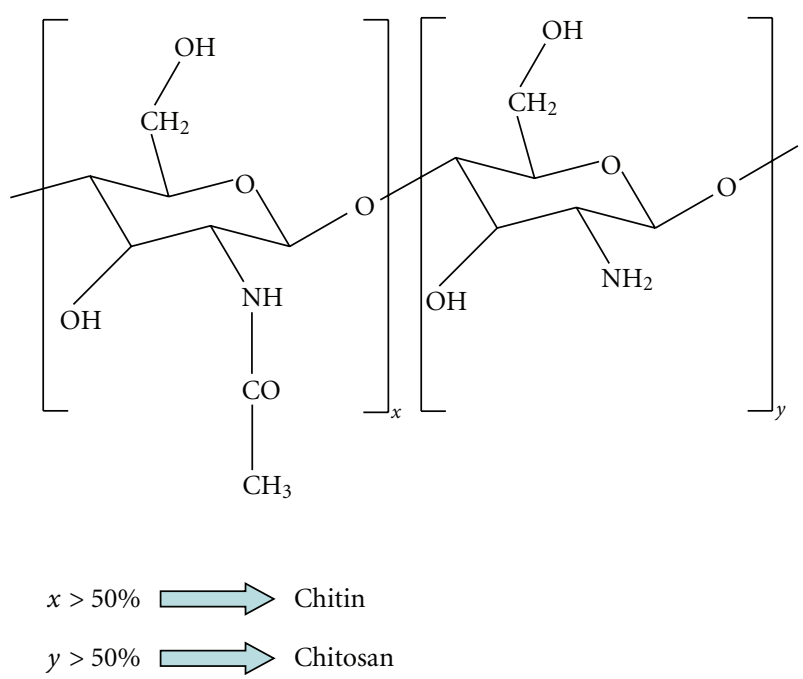

FIGURE 1: Molecular structures of chitin and CS.

Both chitin and CS have excellent material properties such as biocompatibility, biodegradability, nontoxicity, as well as chemical and physical stability [12]. Chitin has been generally used in hemostasis and oral dosage excipient. It is also a competent biomaterial in wound healing, anti-inflammation, cholesterol modulation, and enzyme immobilization [13]. CS-based implants, the biocompatible materials with the host tissue, showed little fibrous encapsulation and chronic inflammation and have been tested for tissue engineering in a number of shapes and physical forms, including porous scaffolds and gels. Excellent porous structures, membranes, blocks, tubes, and beads have been obtained by lyophilization $[5,13]$. $\alpha$ Chitin whisker-reinforced CS nanocomposite films were prepared using solution-casting technique. The increase in the tensile strength of the nanocomposite films with increasing $\alpha$-chitin whisker content could be attributed to the interaction between CS molecules and $\alpha$-chitin whiskers via hydrogen bonding [14]. However it is difficult to prepare 3dimensional chitosan rod by Twin Screw Extruder or Single Screw Extruder, because there are stronger intramolecular and intermolecular H-bonds in chitosan, which make the melting temperature of chitosan higher than its decomposing temperature. Novel 3-dimensional CS rod with layer-bylayer structure and its composite rod with multifunctional properties have been constructed via in situ precipitation method by our group (Figure 2) [15-18]. It can be used as bioabsorbable devices for internal fixation, which not only reduce stress shielding to the bone but also avoid a second operation for removal [19]. In this study, CHF/CS composite rods with layer-by-layer structure were prepared by in situ precipitation method. The forming mechanism, microstructure morphology and mechanical properties of $\mathrm{CHF} / \mathrm{CS}$ composite rods were explored in the following sections.

\section{Materials and Experiments}

2.1. Materials. The materials are CS (Biomedical grade, $M_{\eta}=5.63 \times 10^{5}$, D.D $=91 \%$, Qingdao Haihui Bioengi-

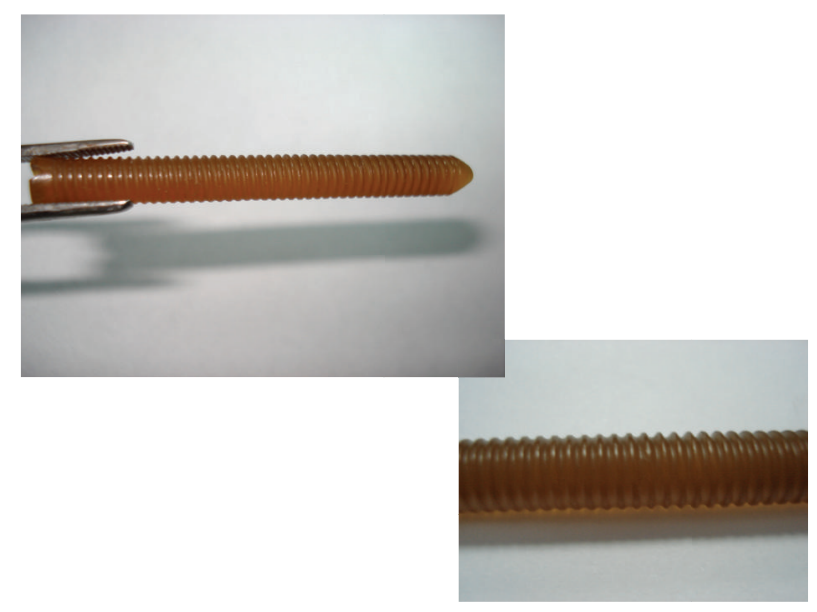

Figure 2: Photo of CS screws.

neering Co., Ltd), chitin fiber (CHF, denier: $2.3 \pm 0.5$ dtex, Weifang Youngdeok Chitosan Co., Ltd), acetic acid (HAc, CP, Yixing Niujia chemical reagent plant), and sodium hydroxide $(\mathrm{NaOH}, \mathrm{AR}$, Hangzhou Xiaoshan chemical reagent corporation). These materials are commercially available and used without further purification.

2.2. Preparation of CHF/CS Composite Rods. Different weight $(0.05 \mathrm{~g}, 0.1 \mathrm{~g}, 0.2 \mathrm{~g}$, and $0.3 \mathrm{~g}$, resp.) of CHFs, which were cut into short fibers $(\sim 5 \mathrm{~mm}$ in length), were added into $400 \mathrm{ml}$ acetic acid aqueous solution (2\%, v/v) and stirred for 0.5 hour. Then $20 \mathrm{~g}$ of CS powder were added and stirred for 2 hours. Finally CHFs were suspended in the viscous CS solution. The resulting solution was statically placed for 24 hours to remove the air bubbles trapped in the viscous liquid. The mixture solution was poured into cylindrical mold and then immerged into sodium hydroxide aqueous solution with a concentration of $5 \%(\mathrm{wt} / \mathrm{v})$ for 6 hours to form $\mathrm{CHF} / \mathrm{CS}$ gel rod. The gel rod was washed with deionized water and air-dried in oven at $60^{\circ} \mathrm{C}$.

2.3. SEM Observations. HITACHI S- 4800 SEM produced by Japan was used to observe the microstructure of the samples which were sputter-coated by gold before observation.

2.4. X-Ray Diffraction Analysis. Crystallinity of the samples was studied with X-ray Diffraction (Rigaku D/max 2550PC) using a monochromatic $\mathrm{Cu} \mathrm{K} \alpha$ radiation generated at $40 \mathrm{kV}$, $300 \mathrm{~mA}$. The samples were scanned from $5^{\circ}$ to $60^{\circ}$ at $10^{\circ} / \mathrm{min}$.

2.5. Thermal Analysis. The TGA of the samples was studied on Pyris-6 Thermo Analyses (TA) apparatus produced by PerkinElmer and measurements were recorded from $50^{\circ} \mathrm{C}$ to $600^{\circ} \mathrm{C}$ at a heating rate of $20^{\circ} \mathrm{C} /$ minute under flow $\mathrm{N}_{2}$ atmosphere (flow rate: $40 \mathrm{ml} /$ minute).

2.6. Testing of Mechanical Properties. All of the samples were air-dried in oven at $60^{\circ} \mathrm{C}$ for 2 hours to remove the moisture 


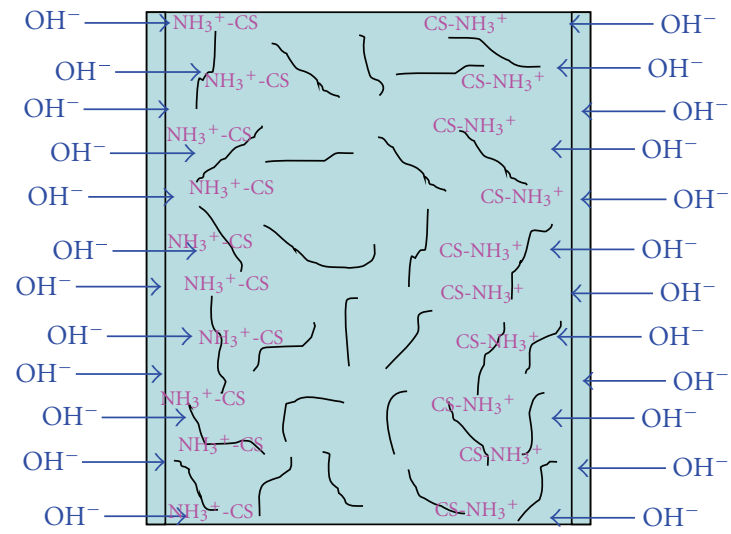

(a)

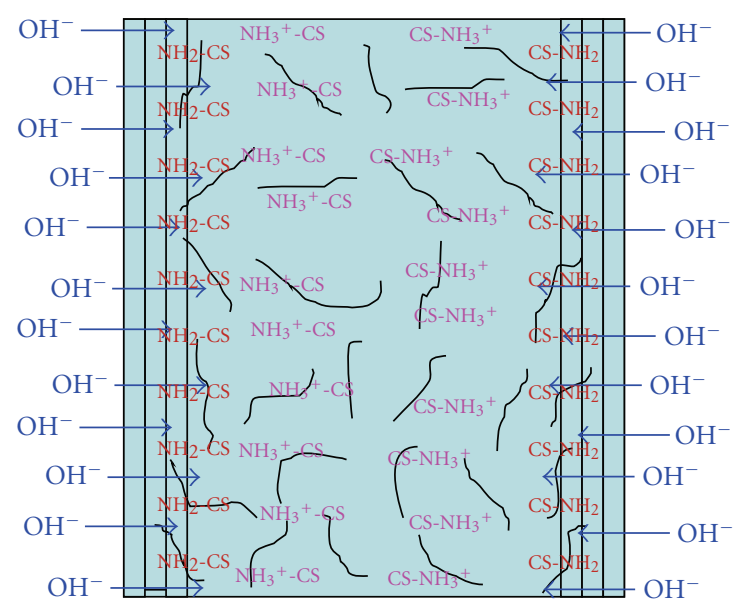

(c)

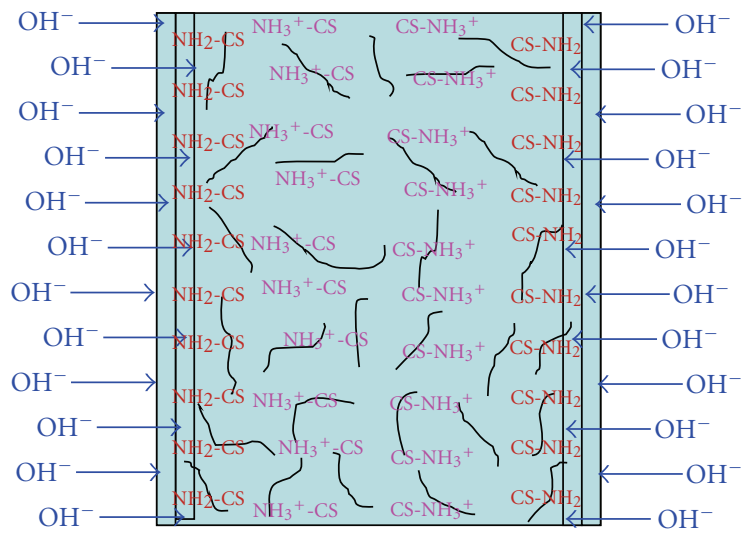

(b)

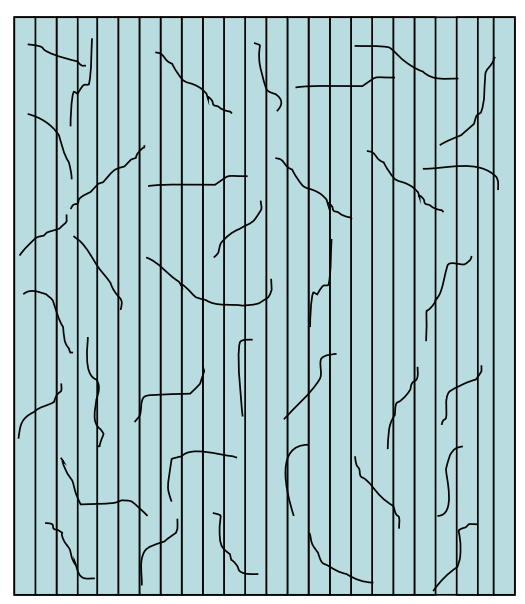

(d)

FIGURE 3: The schematic representation about forming process of CHF/CS gel rod with layer-by-layer structure (vertical section).
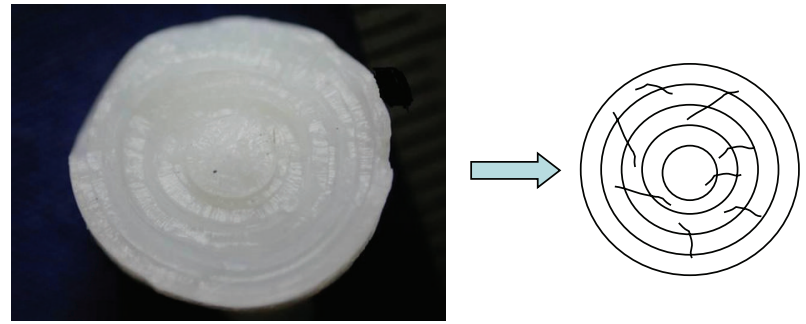

Figure 4: Layer-by-layer structure of CHF/CS gel rod (cross section).

before testing. Bending strength and bending modulus were determined by three-point bending tests (five rods per group), which were performed on the universal materials testing machine made by Shenzhen Reger Company (Shenzhen, China). The span length was $40 \mathrm{~mm}$ and loading rate was $2 \mathrm{~mm} / \mathrm{min}$.

\section{Results and Discussion}

3.1. Forming Mechanism of CHF/CS 3D Composite Rods. The forming process of CHF/CS gel rod with layer-by-layer structure was shown in Figure 3. The solubility of CS largely depends on the $\mathrm{pH}$ value of environments because of the existence of amino groups. The free amino group of CS was protonated to $\mathrm{CS}-\mathrm{NH}_{3}{ }^{+}$at $\mathrm{pH}=4.2[20,21]$, but when $\mathrm{CS}-\mathrm{NH}_{3}{ }^{+}$encountered massive $\mathrm{OH}^{-}, \mathrm{CS}$ would be precipitated, as shown in what follows:

$$
\begin{gathered}
\mathrm{CS}-\mathrm{NH}_{2}+\mathrm{HAc} \longrightarrow \mathrm{CS}-\mathrm{NH}_{3}{ }^{+}+\mathrm{Ac}^{-}, \\
\mathrm{CS}-\mathrm{NH}_{3}{ }^{+}+\mathrm{OH}^{-} \longrightarrow \mathrm{CS}-\mathrm{NH}_{2}(\downarrow)+\mathrm{H}_{2} \mathrm{O} .
\end{gathered}
$$

However CHFs could not be dissolved in acetic acid aqueous solution, so that they dispersed in the viscous CS solution. The mixture solution was charged into semipermeable template which could separate the CHF/CS solution from $\mathrm{NaOH}$ solution, so that small molecules and ions such as $\mathrm{H}_{2} \mathrm{O}, \mathrm{Na}^{+}, \mathrm{OH}^{-}$, and $\mathrm{Ac}^{-}$could permeate except for CS macromolecules (Figure 3(a)). Due to the concentration gradient of alkali between inside and outside of the semipermeable template, $\mathrm{OH}^{-}$could diffuse from outside into $\mathrm{CHF} / \mathrm{CS}$ solution and react with $\mathrm{CS}-\mathrm{NH}_{3}{ }^{+}$. As a result, protonated CS was precipitated in situ to form one layer adhering to semipermeable template closely (Figure 3(b)). As 


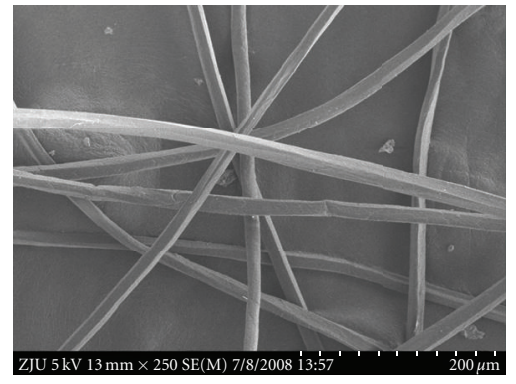

(a)

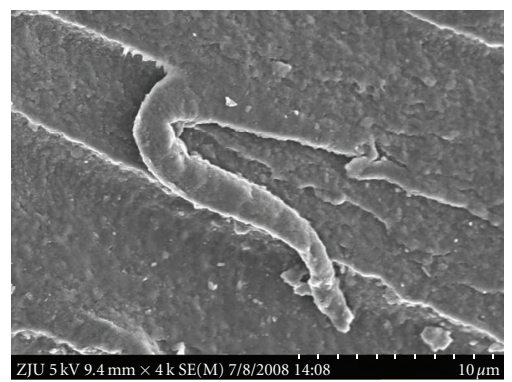

(d)

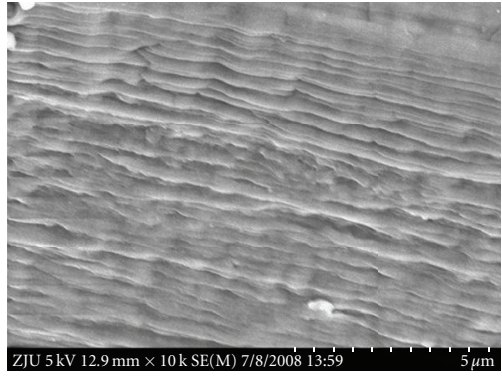

(b)

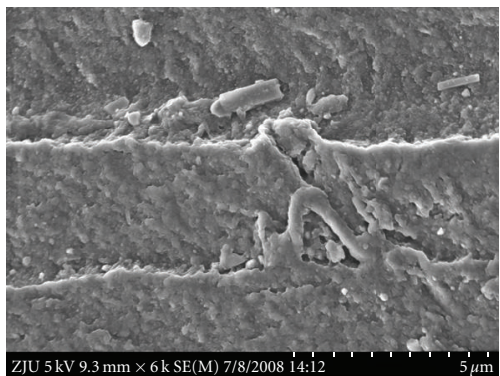

(e)

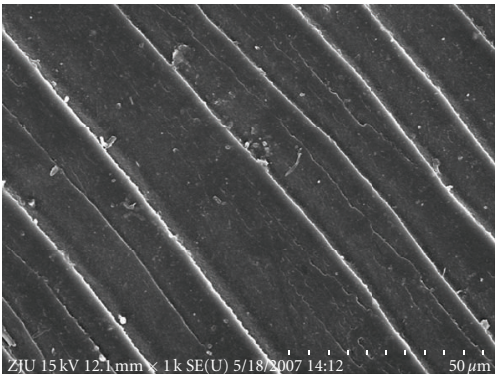

(c)

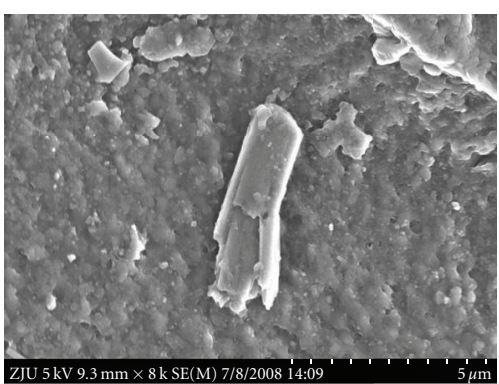

(f)

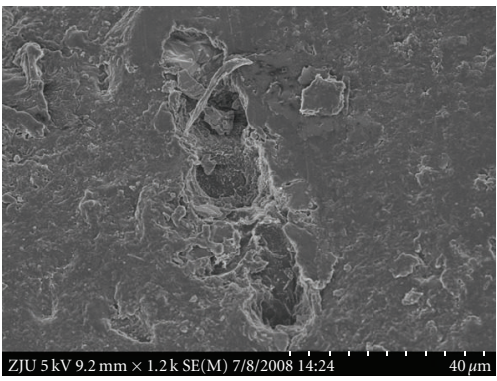

(g)

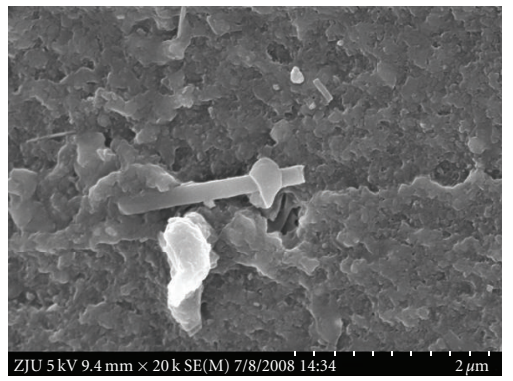

(h)

FIGURE 5: SEM micrographs of (a) CHF $(\times 250)$, (b) CHF $(\times 10,000)$, (c) CS rod $(\times 1000),(\mathrm{d})$ CHF/CS $(0.25 / 100, \mathrm{wt} / \mathrm{wt})(\times 4000),(\mathrm{e})$ CHF/CS (0.5/100, wt/wt) (×6000), (f) CHF/CS (0.5/100, wt/wt) $(\times 8000),(\mathrm{g}) \mathrm{CHF} / \mathrm{CS}(1 / 100, \mathrm{wt} / \mathrm{wt})(\times 1200)$, and $(\mathrm{h}) \mathrm{CHF} / \mathrm{CS}(1.5 / 100$, wt/wt $)(\times 2000)$.

the diffusion process continuing, CS precipitated layer-bylayer to from concentric circle structure (Figures 3(c), 3(d), and 4). At the same time, CHFs were embedded in the CS matrix. Then CHF/CS gel rods were dried and layers became much tighter due to the shrinkage stress.

3.2. Microstructure Morphology of CHF/CS 3D Composites. Microstructure morphology of the CHF, CS rod, CHF/CS $(0.25 / 100, \mathrm{wt} / \mathrm{wt}), \mathrm{CHF} / \mathrm{CS}(0.5 / 100, \mathrm{wt} / \mathrm{wt}), \mathrm{CHF} / \mathrm{CS}$ $(1 / 100, \mathrm{wt} / \mathrm{wt})$, and CHF/CS $(1.5 / 100, \mathrm{wt} / \mathrm{wt})$ was shown in Figure 5. The size of CHF was $\sim 10 \mu \mathrm{m}$ in width. The fiber was not in column form but had several edges. And when it was magnified by 10,000 (Figure 5(b)), undulate surface could be seen, so that the sufficient rough surface and edges of the fiber could potentially enhance the mechanical combining stress between fiber and matrix. Layer-by-layer structure could be clearly seen on the cross-section of pure CS rod in Figure 5(c), which was in accordance with the schematic representation about forming process of CHF/CS gel rod. One fiber with CS adhered on the surface traversed several layers in Figure 5(d). And fiber embedded in CS matrix along with the layer could be seen in Figures 5(e) and 5(h). Fiber was pulled out from CS matrix and chipped facet edge could be observed in Figure 5(f), and holes with fiber fragments remained in CS matrix were very shallow (Figure $5(\mathrm{~g})$ ), indicating that interface between fiber and matrix was combined so tightly. CS was the continuous phase that could transfer stress, whereas CHF was randomly dispersed in CS matrix to connect layers of the rod and could endure outside stress.

3.3. Crystallization Property of Samples. XRD patterns of pure CS rod, CHF, and CHF/CS rod $(0.5 / 100, \mathrm{wt} / \mathrm{wt})$ were shown in Figure 6. The peaks at $2 \theta$ of $10.6^{\circ}$ and $20.4^{\circ}$ are characteristic diffraction peaks of CS (Figure 6(a)). Ratana Rujiravanit reported that $\alpha$-chitin whiskers exhibited two major scattering peaks at $2 \theta$ of $\sim 9^{\circ}$ and $\sim 19^{\circ}$ [14]. At the same time, $2 \theta$ of CHF shown in Figure 6(b) were 


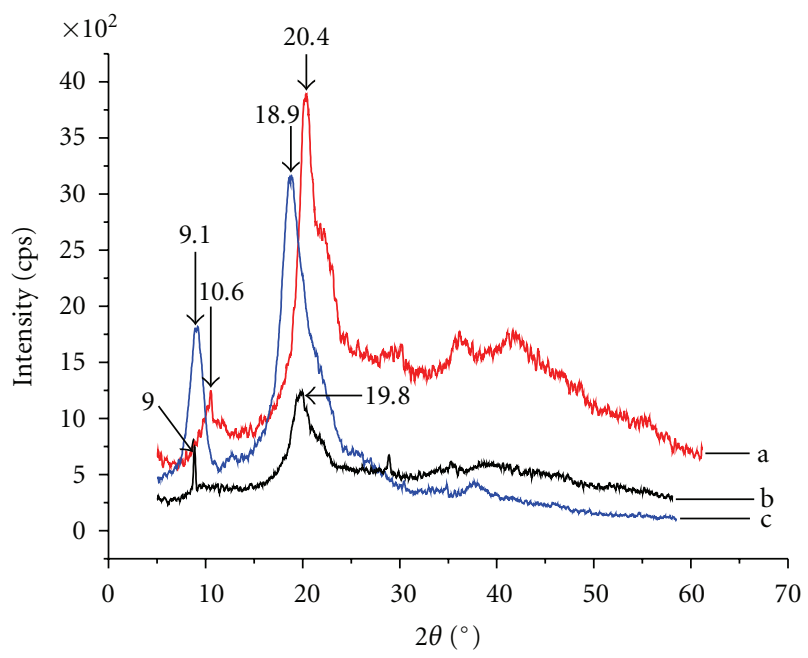

FIGURE 6: XRD patterns for (a) CS rod, (b) CHF, and (c) CHF/CS $(0.5 / 100, w t / w t)$.

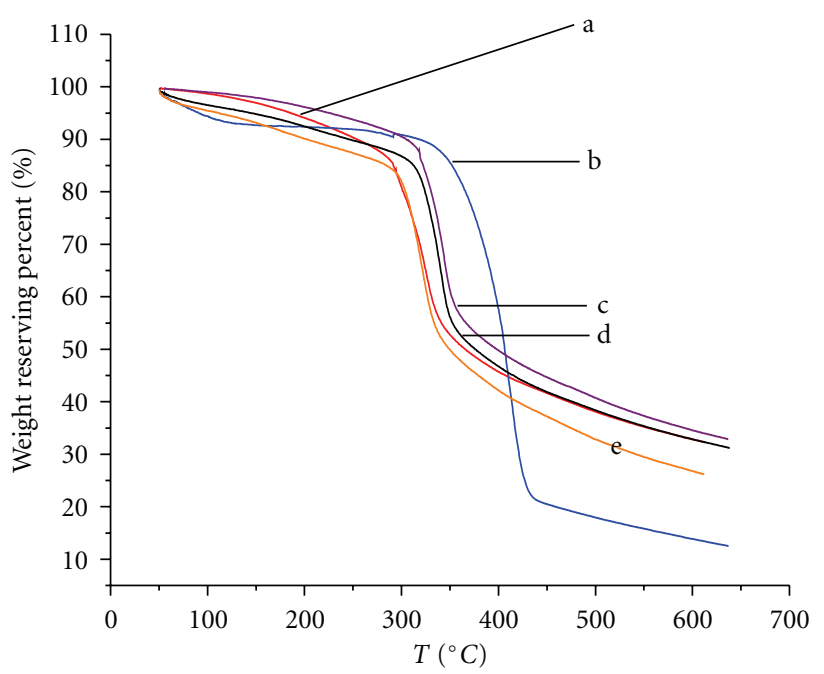

Figure 7: TG curves for (a) CS rod, (b) CHF, (c) CHF/CS (0.25/100, $\mathrm{wt} / \mathrm{wt}),(\mathrm{d}) \mathrm{CHF} / \mathrm{CS}(0.5 / 100, \mathrm{wt} / \mathrm{wt})$, and (e) CHF/CS $(1 / 100$, $\mathrm{wt} / \mathrm{wt}$ ), in the $50-600^{\circ} \mathrm{C}$ temperature range under $\mathrm{N}_{2}$ atmosphere.

$9.1^{\circ}$ and $18.9^{\circ}$, respectively, which were in accordance with previous research. While small amount of CHF was added into CS matrix, two diffraction peaks shifted to $9.0^{\circ}$ and $19.8^{\circ}$, and intensity of the peaks decreased compared with pure CS rod and pure CHF (Figure 6(c)), indicating strong interactions between CS and CHF, resulting in the reduction of crystallinity of CHF/CS composites. According to the Bragg equation $(2 d \sin \theta=n \lambda)$, CS crystal plane spacing $(d)$ of CHF/CS composites has been become larger than that of pure CS rod.

3.4. Thermal Properties of CHF/CS Composites. The thermal gravimetric (TG) curves of CS rod, CHF, CHF/CS (0.25/100, $\mathrm{wt} / \mathrm{wt}), \mathrm{CHF} / \mathrm{CS}(0.5 / 100, \mathrm{wt} / \mathrm{wt})$, and CHF/CS $(1 / 100$, $\mathrm{wt} / \mathrm{wt}$ ) were shown in Figure 7 , which were tested in the

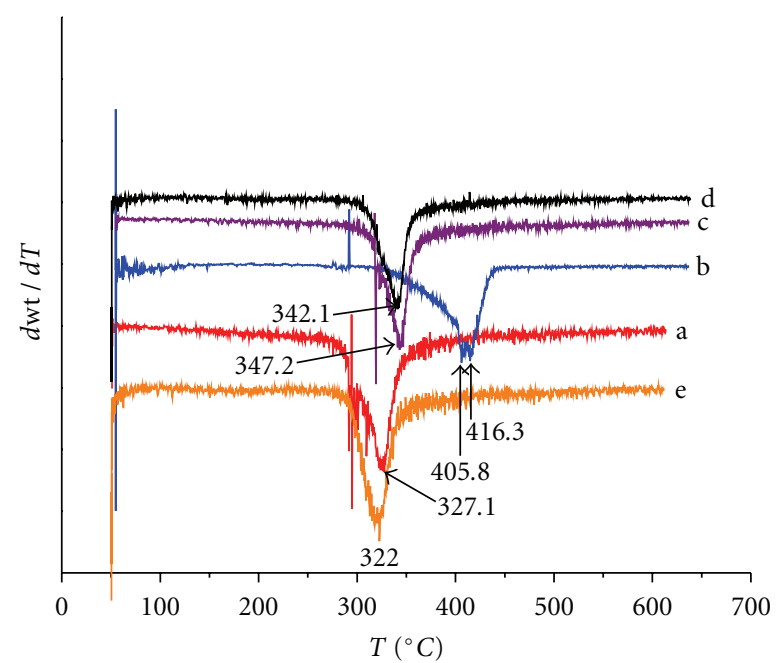

Figure 8: DTG curves for (a) CS rod, (b) CHF, (c) CHF/CS (0.25/100, wt/wt), (d) CHF/CS (0.5/100, wt/wt), and (e) CHF/CS $(1 / 100, w t / w t)$, in the $50-600^{\circ} \mathrm{C}$ temperature range under $\mathrm{N}_{2}$ atmosphere.

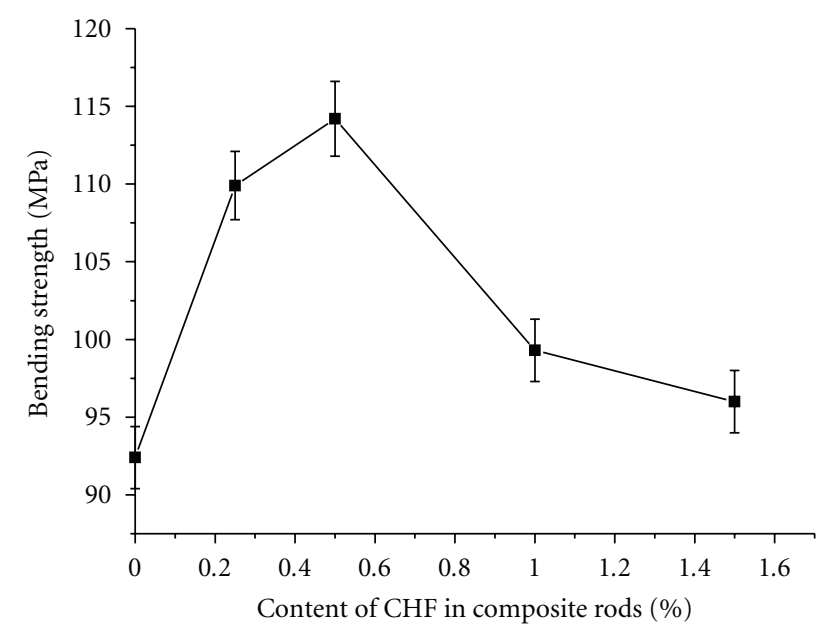

FIGURE 9: Bending strength of CHF/CS composites influenced by content of CHF.

50-600 ${ }^{\circ} \mathrm{C}$ temperature range under $\mathrm{N}_{2}$ atmosphere. The temperatures about different mass residual percentage $\left(T_{\mathrm{mr}}\right)$ of the samples were listed in Table 1. When a little CHF was added into CS matrix $(\mathrm{CHF} / \mathrm{CS}=0.25 / 100, \mathrm{wt} / \mathrm{wt})$, $T_{\mathrm{mr}}$ of CHF/CS composite was higher than that of pure CS rod. Along with increasing content of CHF, $T_{\mathrm{mr}}$ of $\mathrm{CHF} / \mathrm{CS}$ composites decreased. The thermal stability of $\mathrm{CHF} / \mathrm{CS}$ $(0.5 / 100, \mathrm{wt} / \mathrm{wt})$ rod was weaker than that of $\mathrm{CHF} / \mathrm{CS}$ $(0.25 / 100, \mathrm{wt} / \mathrm{wt})$ rod but slightly better than that of pure $\mathrm{CS}$ rod. When the ratio of CHF/CS arrived at $1 / 100(\mathrm{wt} / \mathrm{wt}$ ), its thermal stability was slightly weaker than that of pure CS rod. In all, thermal stability of CS rod could be enhanced by incorporating little CHF, but decreased at higher content of CHF.

Differential thermogravimetric (DTG) curves of the samples were shown in Figure 8. The temperatures of the fastest 
TABLE 1: The temperatures about mass residual percentage of samples $\left(/{ }^{\circ} \mathrm{C}\right)$.

\begin{tabular}{|c|c|c|c|c|c|}
\hline Mass residual percentage & CS rod & $\mathrm{CHF}$ & $\begin{array}{c}\text { CHF/CS } \\
(0.25 / 100, \text { wt/wt })\end{array}$ & $\begin{array}{c}\text { CHF/CS } \\
(0.5 / 100, w t / w t)\end{array}$ & $\begin{array}{c}\mathrm{CHF} / \mathrm{CS} \\
(1 / 100, w \mathrm{wt} / \mathrm{wt})\end{array}$ \\
\hline $90 \%$ & 253.9 & 318.2 & 305.4 & 245.8 & 202.2 \\
\hline $70 \%$ & 319.1 & 384.6 & 341.8 & 336.3 & 316.6 \\
\hline $50 \%$ & 365.7 & 406.4 & 398.2 & 375.9 & 349.6 \\
\hline
\end{tabular}

weight loss rate $\left(T_{\mathrm{fl}}\right)$ of $\mathrm{CHF}$ were $405.8^{\circ} \mathrm{C}$ and $416.3^{\circ} \mathrm{C}$. The $T_{\mathrm{fl}}$ of CS rod, CHF/CS $(0.25 / 100, \mathrm{wt} / \mathrm{wt}), \mathrm{CHF} / \mathrm{CS}(0.5 / 100$, $\mathrm{wt} / \mathrm{wt})$, and $\mathrm{CHF} / \mathrm{CS}\left(1 / 100\right.$, wt/wt) were $327.1^{\circ} \mathrm{C}, 347.2^{\circ} \mathrm{C}$, $342.1^{\circ} \mathrm{C}$, and $322.0^{\circ} \mathrm{C}$, respectively. Obviously, the $T_{\mathrm{fl}}$ of CHF/CS (0.25/100, wt/wt) and CHF/CS (0.5/100, wt/wt) was higher than pure CS rod, indicating that the thermal stability of CHF/CS is enhanced by adding little CHF. But the $T_{\mathrm{fl}}$ of CHF/CS (1/100, wt/wt) was lower than that of pure CS rod, so that the thermal stability of CHF/CS composite decreased.

3.5. Mechanical Properties of CHF/CS Composite Rods. Chitin whiskers were used to reinforce CS nanocomposite films successfully. When there were $2.96 \%$ (wt $\%$ ) chitin whiskers in the composite films, the tensile strength of nanocomposite films could arrive at $83.8 \pm 2.9 \mathrm{MPa}$, while the tensile strength of pure CS films was $64.9 \pm 0.7 \mathrm{MPa}$ [14]. The mechanical properties of CHF/CS composite rods were shown in Figure 9. The bending strength of CHF/CS composites was increased first and then reduced along with the increasing of the content of CHF. Bending strength and bending modulus of pure CS rods are $92.4 \mathrm{MPa}$ and $4.1 \mathrm{GPa}$, respectively. When $0.5 \%$ CHF was added into CS matrix, the bending strength and bending modulus of composite rod maximized at $114.2 \mathrm{MPa}$ and $5.2 \mathrm{GPa}$, respectively, increased by $23.6 \%$ and $26.8 \%$ compared with pure CS rods. When much more CHF was added into CS matrix, the mechanical properties of composite rods were reduced due to much more fiber tips as stress concentrators.

\section{Conclusions}

$\mathrm{CHF}$ and CS 3D composite rods with layer-by-layer structure were constructed by in situ precipitation method. CHF could be suspended in the viscous CS solution since CHF could not be dissolved in acetic acid aqueous solution, while CS could be dissolved due to the different D.D between CHF and CS. Undulate surface of CHF seen using SEM demonstrated that sufficient rough surfaces and edges of the fiber could enhance the mechanical combining stress between fiber and matrix. Microstructure morphology also indicated that interface between fiber and matrix was combined tightly. CS was the continuous phase that can transfer stress, whereas $\mathrm{CHF}$ was random dispersed in CS matrix to connect layers of the rod and could endure outside stress. While small amount of CHF was added into CS matrix, intensity of the peaks decreased compared with pure CS rod and pure CHF, showing that crystallinity of CHF/CS composites decreased. CS crystal plane spacing $(d)$ of CHF/CS composites has become larger than that of pure CS rod. Mixed little CHF could enhance thermal stability of CS rod to an optimum and higher content of CHF would decrease its thermal stability. When $0.5 \%$ CHF was added into CS matrix, the bending strength and bending modulus of composite rods maximized at $114.2 \mathrm{MPa}$ and $5.2 \mathrm{GPa}$, respectively, increased by $23.6 \%$ and $26.8 \%$ compared with pure CS rods. Thus, CHF/CS composite rods could be a novel biomedical device used for bone fracture internal fixation.

\section{Acknowledgment}

This work was funded by the National Natural Science Foundation of China (Grant No. 50773070), the Key Basic Research Development Plan (Project 973) of China (Grant No. 2005CB623902) and Grand Science and Technology Special Project of Zhejiang Province (Grant No. 2008C11087).

\section{References}

[1] L. Chen, Y. Du, H. Wu, and L. Xiao, "Relationship between molecular structure and moisture-retention ability of carboxymethyl chitin and chitosan," Journal of Applied Polymer Science, vol. 83, no. 6, pp. 1233-1241, 2002.

[2] D. Suzuki, M. Takahashi, M. Abe et al., "Comparison of various mixtures of $\beta$-chitin and chitosan as a scaffold for three-dimensional culture of rabbit chondrocytes," Journal of Materials Science: Materials in Medicine, vol. 19, no. 3, pp. 1307-1315, 2008.

[3] K. Kurita, "Chitin and chitosan: functional biopolymers from marine crustaceans," Marine Biotechnology, vol. 8, no. 3, pp. 203-226, 2006.

[4] E. Agulló, M. S. Rodríguez, V. Ramos, and L. Albertengo, "Present and future role of chitin and chitosan in food," Macromolecular Bioscience, vol. 3, no. 10, pp. 521-530, 2003.

[5] B. Krajewska, "Membrane-based processes performed with use of chitin/chitosan materials," Separation and Purification Technology, vol. 41, no. 3, pp. 305-312, 2005.

[6] T. Honma, T. Senda, and Y. Inoue, “Thermal properties and crystallization behaviour of blends of $\operatorname{poly}(\varepsilon$-caprolactone) with chitin and chitosan," Polymer International, vol. 52, no. 12, pp. 1839-1846, 2003.

[7] K. Van De Velde and P. Kiekens, "Structure analysis and degree of substitution of chitin, chitosan and dibutyrylchitin by FT-IR spectroscopy and solid state13C NMR," Carbohydrate Polymers, vol. 58, no. 4, pp. 409-416, 2004.

[8] E. Khor and L. Y. Lim, "Implantable applications of chitin and chitosan,” Biomaterials, vol. 24, no. 13, pp. 2339-2349, 2003.

[9] R. Jayakumar, N. Selvamurugan, S. V. Nair, S. Tokura, and H. Tamura, "Preparative methods of phosphorylated chitin and chitosan-an overview," International Journal of Biological Macromolecules, vol. 43, no. 3, pp. 221-225, 2008.

[10] T. Wu and S. Zivanovic, "Determination of the degree of acetylation (DA) of chitin and chitosan by an improved first 
derivative UV method," Carbohydrate Polymers, vol. 73, no. 2, pp. 248-253, 2008.

[11] M. Rinaudo, "Chitin and chitosan: properties and applications," Progress in Polymer Science, vol. 31, no. 7, pp. 603-632, 2006.

[12] V. G. Mir, J. Heinämäki, O. Antikainen et al., "Direct compression properties of chitin and chitosan," European Journal of Pharmaceutics and Biopharmaceutics, vol. 69, no. 3, pp. 964-968, 2008.

[13] Y.-C. Kuo and I.-N. Ku, "Cartilage regeneration by novel polyethylene oxide/chitin/chitosan scaffolds," Biomacromolecules, vol. 9, no. 10, pp. 2662-2669, 2008.

[14] J. Sriupayo, P. Supaphol, J. Blackwell, and R. Rujiravanit, "Preparation and characterization of $\alpha$-chitin whiskerreinforced chitosan nanocomposite films with or without heat treatment," Carbohydrate Polymers, vol. 62, no. 2, pp. 130-136, 2005.

[15] Q. L. Hu, X. Z. Qian, B. Q. Li, and J. C. Shen, "Studies on chitosan rods prepared by in situ precipitation method," Chemical Journal of Chinese Universities-Chinese, vol. 24, no. 3, pp. 528-531, 2003.

[16] Z. K. Wang, Q. L. Hu, X. G. Dai, H. Wu, Y. X. Wang, and J. C. Shen, "Preparation and characterization of cellulose fiber/chitosan composites," Polymer Composites, vol. 30, no. 10, pp. 1517-1522, 2009.

[17] Z. K. Wang, Q. L. Hu, and L. Cai, "Chitosan and multi-walled carbon nanotube composite rods," Chinese Journal of Polymer Science. In press.

[18] Z. K. Wang and Q. L. Hu, "Chitosan rods reinforced by Ncarboxyl propionyl chitosan sodium," Acta Physico-Chimica Sinica. In press.

[19] A. Yang and R. Wu, "Mechanical properties and interfacial interaction of a novel bioabsorbable chitin fiber reinforced poly ( $\varepsilon$-caprolactone) composite," Journal of Materials Science Letters, vol. 20, no. 11, pp. 977-979, 2001.

[20] Q. Hu, B. Li, M. Wang, and J. Shen, "Preparation and characterization of biodegradable chitosan/hydroxyapatite nanocomposite rods via in situ hybridization: a potential material as internal fixation of bone fracture," Biomaterials, vol. 25, no. 5, pp. 779-785, 2004.

[21] B. Q. Li, D. C. Jia, Y. Zhou, Q. L. Hu, and W. Cai, "In situ hybridization to chitosan/magnetite nanocomposite induced by the magnetic field," Journal of Magnetism and Magnetic Materials, vol. 306, no. 2, pp. 223-227, 2006. 

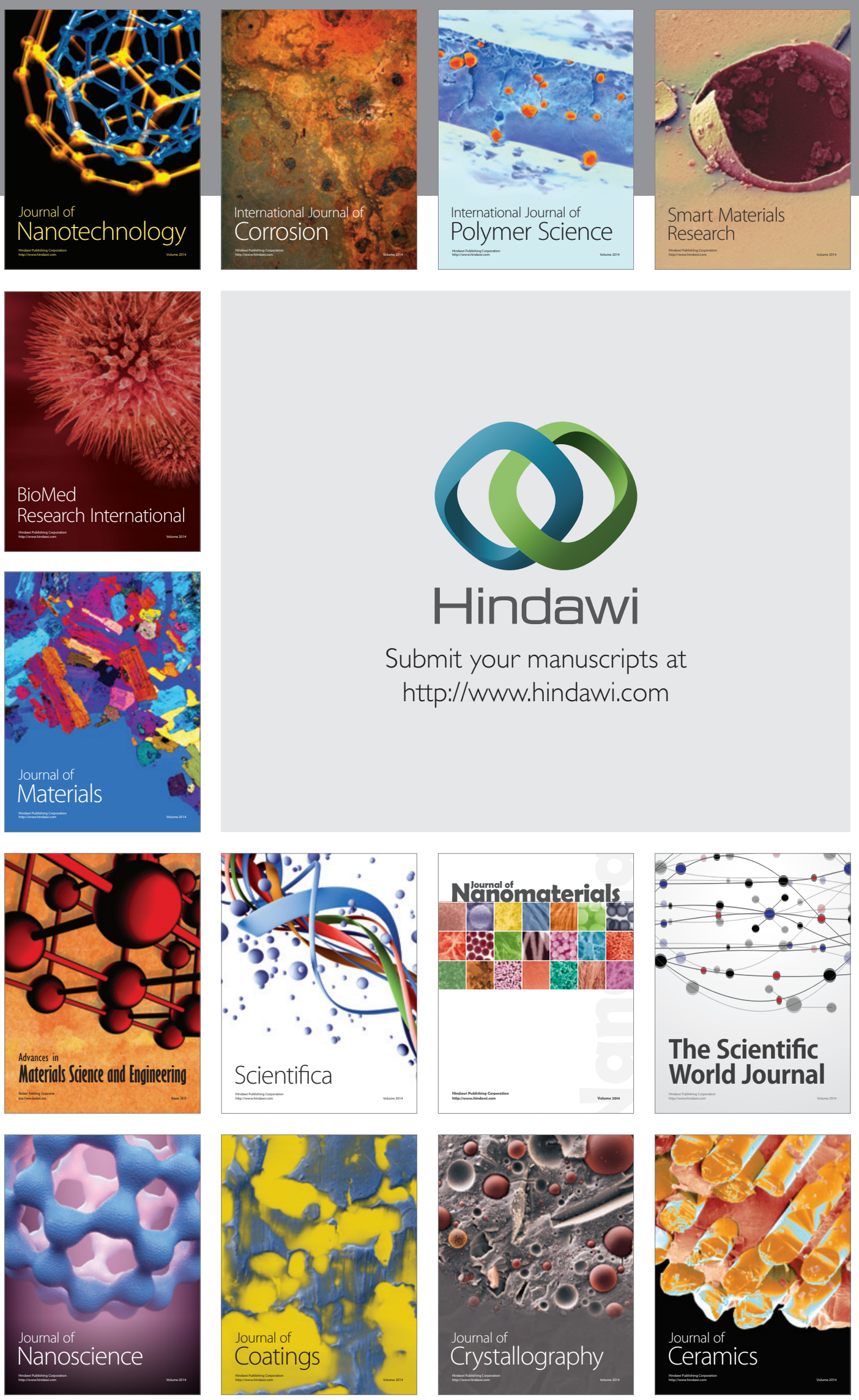

The Scientific World Journal

Submit your manuscripts at

http://www.hindawi.com

\section{World Journal}

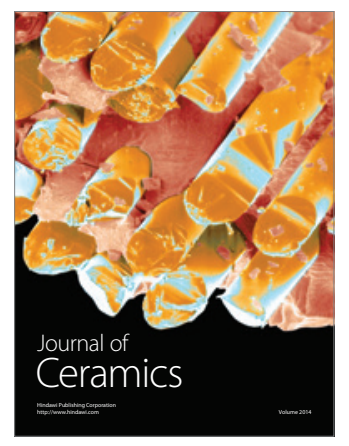

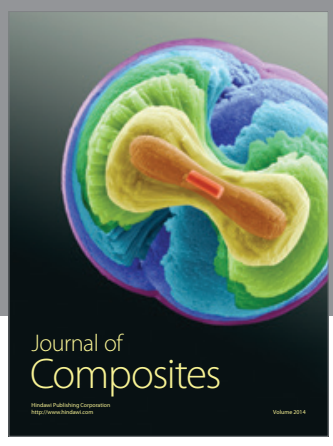
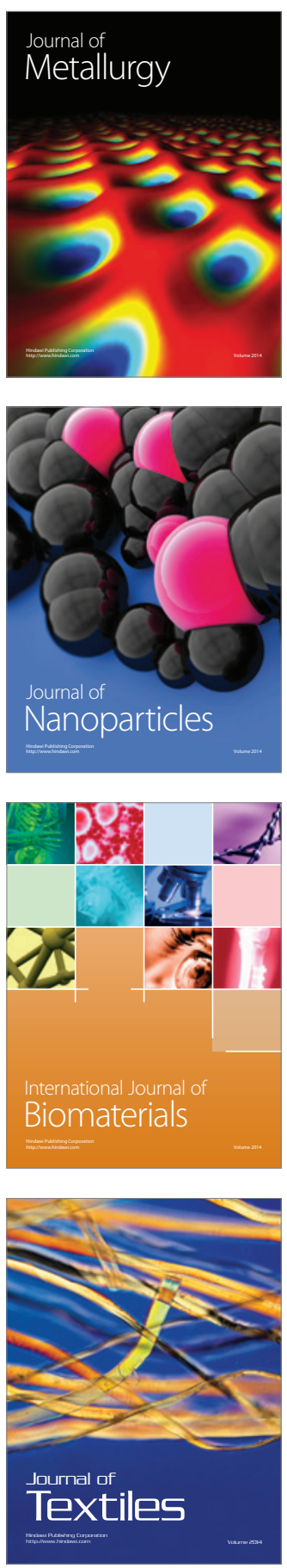